\title{
Санкт-Петербург и русский двор
}

\author{
Майя Борисовна Лавринович \\ Национальный исследовательский университет «Высшая школа экономики» \\ mlavrinovich@hse.ru
}

Paul Keenan, St. Petersburg and the Russian Court, 1703-1761 (London: Palgrave Macmillan, 2013). ISBN 9781137311597

Монография Пола Кинана Санкт-Петербург и русский двор в 1703-1761 годах принадлежит к ряду работ, которые можно было бы объединить тематикой constructing an imperial capital. $^{1}$ В отличие от монографии Джорджа Манро о Петербурге екатерининского времени, вышедшей несколькими годами ранее, ${ }^{2}$ это книга не является попыткой “плотного описания” внутренней жизни города в ее связи с социально-экономическими процессами в империи: в ней есть только два “действующих лица" - двор и город, город в его пространственном и социальном измерениях. Эта книга - попытка показать синтез нового, европеизирующегося двора и нового города, построенного специально для того, чтобы европеизировать всю страну. Автор предлагает один из способов написания социо-культурной истории имперской столицы в XVIII веке: двор служит точкой отсчета, от которой расходятся “круги” по городу.

Эта книга - ни в коем случае не история строительства и заселения Петербурга, даже не попытка его социальной истории (какой является монография О.Е. Кошелевой ${ }^{3}$, но попытка представить город как место, где зарождались и находили свое развитие самые значимые в истории России культурные и социальные перемены. Источником этих перемен, его инициатором и локусом, собственно, и был двор с его повседневной жизнью и ритуалами, воздействовавшими и формировавшими церемониальную и общественную стороны жизни города. Петербург был местом, где зарождались социальная среда и социальные отношения (в значении “отношения в социуме") не из “старомосковских" форм и отношений, а на новом, неосвоенном месте и в совершенно ином пространстве. Именно в этом городе появились новые, носившие эксплицитно выраженный европейский характер, формы социального взаимодействия, затрагивавшие прежде всего элиту (с. 23). Эти формы были хорошо узнаваемы иностранными дипломатами и военными, благодаря чему их мемуары и дневники - основной источник, использованный автором монографии.

В деталях отталкиваясь от написанных на архивных документах фундаментальных трудов О.Г. Агеевой об императорском дворе XVIII века, ${ }^{4}$ а также от

\footnotetext{
${ }^{1}$ См. библиографию последних работ о Петербурге в рецензии: Gary Marker. Review of Munro, George E., The Most Intentional City: St. Petersburg in the Reign of Catherine the Great. H-Urban, H-Net Reviews. March, 2009. URL: http://www.h-net.org/reviews/showrev.php?id=23507 [последнее обращение: 20.09.2014].

${ }^{2}$ George E. Munro, The Most Intentional City: St. Petersburg in the Reign of Catherine the Great (Madison: Fairleigh Dickinson University Press, 2008).

${ }^{3}$ О. Е. Кошелева, Люди Санкт-Петербургского острова петровского времени (Москва: ОГИ, 20о4).

${ }^{4}$ О. Г. Агеева, Императорский двор России, 170о-1796 годы (Москва: Наука, 20о8).
} 
монографии Д.Д. Зелова, выстроившего хронологию и типологию состоявшихся в Петербурге фейерверков и триумфальных въездов, ${ }^{5}$ Кинан пытается воссоздать структуру взаимоотношений между двором, элитой и городом и показать эту связь как органическую. И если Эрнест Зицер в своей монографии о “царстве Преображения" предъявляет читателю двор как культурный и политический феномен в его обособленном виде, анализируя придворные зрелища и “потешную” иерархию и риторику, а Ричард Уортман, изучая символический и эмблематический ряды торжеств и церемоний, ищет в них происхождение “мифа о власти” российской монархии, то Кинан показывает связь двора с социальной и культурной средой города, пытается нащупать точки его пересечения с внешним миром. Тема европеизации структурирует монографию благодаря тому, что сам Петербург историк исследует как сознательно созданный локус, источник распространявшихся по всей России социальных и культурных перемен. И в этом смысле исследование двора является очень “европейским,” поскольку в культуре раннего Нового времени двор занимал центральное место, сосредоточивая на себе также и “народный” интерес. Под европеизацией - термин, который автор предпочитает “модернизации" или “вестернизации,” - Кинан, вслед за Джеймсом Кракрафтом, ${ }^{6}$ автором монографии о петровской “культурной революции,” понимает “ассимиляцию или ... присвоение до некоторой степени европейских культурных практик и норм” (с. 6). Весь Петербург, его внешний вид, институции, социальная и культурная жизнь - все несет на себе приметы его связи с современными ему дворами и городами-резиденциями Европы. Однако временами, как представляется, автор переоценивает “европеизирующий” потенциал двора или же отчасти пересматривает выводы Э. Зицера, показавшего, что двор петровского времени - образование, носившее значительно более сложный характер, чем просто “западнический” или “светский.” Совершенно определенно на этот счет мнение Р. Уортмана: русский двор только по виду походил на западноевропейские дворы, дворяне лишь подражали европейцам, но оставались при этом русскими, то есть вели себя “как иностранцы.” Однако именно это противоречие позволяло им, по мнению Уортмана, управлять страной. ${ }^{8}$

Собственно к двору, к тому, что он представлял собой, Кинан переходит лишь в начале третьей главы. Российский двор первой половины XVIII века автор считает разновидностью двора раннего Нового времени, разделяя его, вслед за Н. Элиасом, на “внутренний” (ближайший круг правящей особы, высшие чины) и “внешний” (прислуга всех уровней). Он, безусловно, принадлежит к европейским дворам, несмотря на то, что выстроить типологию дворов сложно, утверждает Кинан, отталкиваясь от современных работ о версальском и венском дворах. Петровский двор, представлявший собой смесь традиции и целесообразности, с момента появления при нем Екатерины, еще даже не состоявшей в браке с Петром I, претерпевает эволюцию в направлении германских дворов, приобретая сходную с ними организацию и чины и укрепляя эту тенденцию за счет браков с членами

5 Д. Д. Зелов, Официальные светские праздники как явление русской культуры конца XVII - первой половины XVIII века: История триумфов и фейерверков от Петра Великого до его дочери Елизаветы (Москва: УРСС, 2002).

${ }^{6}$ James Cracraft, The Revolution of Peter the Great (Cambridge, MA: Harvard University Press, 2003).

${ }^{7}$ См.: Э. А. Зицер, Царство Преображения: Священная пародия и царская харизма при дворе Петра Великого (Москва: НЛО, 2008).

${ }^{8}$ Р. С. Уортман, Сценарии власти: Мифы и церемонии русской монархии от Петра Великого до смерти Николая I (Москва: ОГИ, 2002), 125. 
правящих семей германских земель. Прослеживаемая историком формальная “генеалогия" петровского двора, а также церемониальных и вообще придворных нововведений создает определенное поле для полемики по вопросу о том, насколько этот двор был европеизированным или “европейским."9

Книга состоит из пяти глав, заголовки которых резюмируют содержание каждой из них, создавая определенную динамику: "Location - Regulation - Organisation - Interaction - Instruction.” В монографии охвачены 22 года петровского правления и 36 лет послепетровской эпохи, насквозь пронизанной явлениями и тенденциями, берущими свое начало в царствовании царя-реформатора, буквально “освещенной” им (с. 2). Описывая церемонии при дворах Анны Иоанновны или Елизаветы Петровны, Кинан постоянно обращается к царствованию Петра и его церемониальным инновациям, соотнося организацию придворной жизни его преемниц с “образцом” начала столетия. Автор во введении справедливо напоминает об уже ставшем банальностью историографическом факте недооценки правлений первых преемниц и преемников Петра. Более того, тенденции этого периода имели во многом решающее значение для понимания приоритетов и действий Екатерины II, как в отношении города, так и в отношении двора.

Первая глава посвящена созданию новых пространств городской жизни в социально-топографическом смысле. С одной стороны, город физически олицетворял российскую связь с остальной Европой. Этот тренд, задававший тон последующее столетие, должен был отчетливо обозначиться созданием “регулярного," строящегося по плану города. С другой стороны, облик города, его официальной части, был довольно эклектичным. Принципиальное воздействие перемещения в Петербург российской элиты состояло в возникновении нового социального окружения, источника новых видов взаимодействия (с. 23). Кинан развивает очень продуктивную идею о том, что сама архитектура - идеальная, регулярная архитектура города раннего Нового времени - не могла, наряду с пространствами, организуемыми ею, не оказывать влияния на события вокруг: на праздничную и церемониальную жизнь города (с. 32).

Глава вторая несколько выбивается из общего ряда, в центре которого находится “двор” в его взаимодействии с городом. Это небольшое отдельное исследование, изучающее регулирование таких сфер городской повседневной жизни как карточные игры, пьянство и “непристойное” поведение. В центре внимания автора - деятельность Главной полицмейстерской канцелярии. Петербург был площадкой для воплощения в жизнь идеи о “полицейском государстве” (well-ordered police state), поэтому городская полиция была весьма важным звеном. Автор стремится показать, как Главная полицмейстерская канцелярия оказывала воздействие на жизнь города, контролируя его отдельные сферы. Таким образом Петербург включался в процесс социального дисциплинирования - структурный процесс эпохи раннего Нового времени, как его описал первый исследователь этого явления Герхард Острайх. В этой главе Кинан анализирует одну из сфер, затронутую процессом социального дисциплинирования, - полицию, а также затрагивает “по касательной” двор, откуда,

\footnotetext{
9 Так, например, А. С. Лавров полагает, что Петр, разрушив церемониал старого двора, не успел создать нового. См.: А. С. Лавров, Колдовство и религия в России. 170о-1740 (Москва: Древлехранилище, 20оо), 345 .
} 
согласно Г. Острайху, дисциплинирование распространяется уже на все общество. ${ }^{10}$ Автор справедливо указывает, что полицейское регулирование - ответ на вызовы раннего Нового времени, с которыми сталкивалось еще допетровское государство во второй половине XVII века. Однако оформлена полицейская администрация была лишь в 1718 году, в одно время с внедрением системы коллегий, что отражало общее стремление государства раннего Нового времени к регулированию всех сфер жизни. В вводной части главы автор подчеркивает, что контроль за такими разными сферами, как санитарное состояние города или нравы жителей города - часть общеевропейской тенденции к регулированию и дисциплинированию общества, и Россия здесь - не исключение. Несмотря на неоднозначность результатов деятельности полиции и продолжавшееся регулирование через законодательство, отмечает автор, само существование Полицмейстерской канцелярии непосредственно помещает Петербург в европейский контекст начала XVIII века (с. 42).

Однако поскольку Главная полицмейстерская канцелярия ни в коем случае не была самостоятельным органом, деятельность Канцелярии в исследуемых сферах городской жизни была заметна в силу того, что этот орган являлся исполнителем указов и инструкций - основного источника, к которому обращается Кинан. Под контроль и репрессии полиции подпадали пьянство, азартные игры и "распутное поведение” (попросту проституция), однако нет никаких свидетельств регулярности этого контроля. Он, очевидно, был выборочным и непостоянным, но автор, чтобы избежать сложного и не всегда продуктивного (в силу особенностей источников) анализа повседневных практик, специально оговаривает, что реакция населения на полицейские законы здесь не рассматривается, поскольку является предметом упомянутого исследования О.Е. Кошелевой. Историк обращает внимание на то, что правительство стало проявлять озабоченность социальными и финансовыми последствиями чрезмерного употребления алкоголя только в послепетровское время: именно тогда появились запреты на прием вещей и домашней утвари в качестве оплаты за алкоголь, а время работы питейных заведений было ограничено во избежание ночных драк и шума (с. 46). Однако в целом и тут Россия и ее население, об особой расположенности которого к пьянству, казалось бы, известно, не выделяются на фоне своих современников: борьба с пьянством была обусловлена стремлением обеспечить “благочиние” в городе, то есть никак не выходила из русла общеевропейской тенденции (с. 46). Регулирование азартных игр было более сложным феноменом. Историк обнаруживает в законодательстве и в мемуарах две стороны этого явления: азартной игры как греха и как вида социальной активности. Особо азартные игры с высокими ставками и возможностями крупных проигрышей ограничивались апартаментами императриц или “знатными дворянскими домами.” Таким образом, четко регулировались пространства, подходящие для этого вида времяпрепровождения, причем подчеркивалась их роль как места взаимодействия, хотя и с заранее распределенными ролями и единственным типом приемлемого поведения. Впрочем, именно здесь автор обнаруживает несколько отличий от европейских практик: отсутствие лицензирования игорных домов и неудача с внедрением лотерей как способов получения дохода государством (с. 53).

Третий аспект регулирования городской жизни - борьба с “непотребным” поведением. Здесь историк обращается к известной истории публичного дома,

${ }^{10}$ См. классическую работу немецкого историка: Gerhard Oestreich, "Strukturprobleme des europäischen Absolutismus," Vierteljahresschrift für soziale und Wirtschaftsgeschichte 55 (1968), 329-347. 
содержавшегося немкой Анной Фелкнер по прозвищу Дрезденша. Его особенность состояла в том, что среди посетителей были представители знатных фамилий, сановники, иностранные министры и офицеры гвардейских полков, - те, кого можно отнести к петербургской элите и даже к придворному кругу. Посещение этого дома определенно было разновидностью социального взаимодействия, однако автор не разрабатывает этот аспект известной истории. Кинан использует не только опубликованные источники, но и обращается к делам, хранящимся в фонде устроенной для расследования и наказания пойманных женщин Калинкинской комиссии в РГАДА. Из дел, содержащих показания Дрезденши, можно понять событийную канву и установить основной круг посетителей ее “вечеров.” Здесь автор остается в традиционном историографическом русле, хотя этот феномен как пример секуляризационных тенденций в законодательстве, a также других модернизационных тенденций заслуживал бы большего внимания. В елизаветинское царствование регулирование доступа в торговые бани - места с определенной репутацией - для разных полов расширяло охват общества дисциплинарными тенденциями, целью которых было насаждение поведения, отвечавшего некоей норме. Источником этой нормы была как церковь, переживавшая с конца XVI века “консервативный поворот,” так и представления о морали, возникшие в кругах элиты, но совсем не соответствовавшие допустимым при дворе практикам. Сдвиг в модели поведения при дворе становится заметным в этот период, отмечает Кинан (с. 53). В книге, где двор является главным объектом исследования, необходимо было, возможно, пойти дальше и показать не только регулирование городской жизни через “полицейское” законодательство, но и дать понять, что русский двор, как двор европейский (а именно эта мысль проходит через всю монографию), был подвержен тенденции дисциплинирования так же, как и другие (в рассматриваемый период отчетливее всего, вероятно, при Елизавете Петровне). Соглашаясь с выводом Кинана, что позиция церкви и воздействие традиционных институтов сформировали определенное расхождение между законодательным, правительственным дискурсом и практикой (с. 53), отмечу, что в книге видны лишь усилия, направленные “вовне," в то время как аналогичные тенденции внутри двора ускользают от авторского внимания. В остальном же, утверждает историк, регулирование повседневной жизни и социальное дисциплинирование в Петербурге были довольно успешны, в отличие от остальных частей страны, где этот процесс сдерживался нехваткой чиновников, отдаленностью от центра и т.п. ${ }^{11}$ Петербург же был резиденцией главной полиции, которая к тому же располагала ясной инструкцией со списком своих обязанностей.

Третья глава - центральная в монографии: она посвящена собственно двору и придворным праздникам. Главные церковные праздники по-прежнему праздновались при дворе, но однако их символический ряд претерпел существенный сдвиг. Не говоря о праздновании побед на новый, европейский, манер, публичными стали прежде “внутренние” торжества царской семьи: свадьбы и похороны; к ним добавился торжественный въезд в Петербург коронованных в Москве правителя или правительницы. Петербург в первой половине века пережил пять свадеб членов

${ }^{11}$ См. об одном из аспектов социального дисциплинирования в России в работе В. М. Живова: В. М. Живов, "Дисциплинарная революция и борьба с суеверием в России XVIII века: «провалы» и их последствия," Антропология революции: Сб. статей по материалам XVI Банных чтений журнала «Новое литературное обозрение» (Москва, 27-29 марта 2008 года), сост. и ред. И. Прохорова, А. Дмитриев и др. (Москва: НЛО, 2009), 327-36о. 
царствующей семьи, причем первым важным событием в этом ряду было замужество племянницы Петра Анны Иоанновны с герцогом Курляндским в 1710 году. Эта церемония и женитьба самого Петра в 1712 году сформировали модель придворной свадьбы, а торжества по поводу бракосочетания наследника престола в 1745 году обозначили новый этап во взаимоотношениях русского двора с европейским церемониалом (с. 77).

Из всех участников и участниц главных придворных церемоний первой половины века единственным членом царской семьи, пережившим в Петербурге, вольно или невольно, их все: свадьбу, торжественный въезд и похороны, - была императрица Анна Иоанновна (если не считать самого Петра I, также сочетавшегося браком и похороненного в Петербурге, но коронованного императором здесь же). Дочь последнего “московского” царя оказалась самой “петербургской” из цариц (до Екатерины II). Участие публики в торжествах по поводу бракосочетаний царских особ не так бросается в глаза, как кардинальные изменения, которые претерпела церемония похорон членов царской семьи. Их важной особенностью была обращенность “во вне,” в то время как традиционные похороны членов царской семьи были закрыты от публики, происходя буквально “внутри” - за кремлевскими стенами. Историк анализирует суть и символическую сторону изменений, которую эта церемония претерпела по сравнению с московскими временами: помимо доступа публики к телу почившего и участия специально приглашенных представителей самых разных социальных групп, из европейской церемонии похорон правителя была заимствована языческая с точки зрения православной церкви практика бальзамирования, не говоря уже об изображении достоинств почившего в виде классических аллегорических фигур. Сам факт погребения в Петербурге означал, что правящая особа навсегда оставалась среди жителей города (с. 85).

Регулярный город требовал церемониального “регулярства": все три главнейшие торжества имели свой сценарий, а их организация иногда даже поражала современников - выходцев из других государств Европы. Еще одно связанное с этим важное нововведение, на которое обращает внимание Кинан, - публикация отчетов о церемониях в Санкт-петербургских ведомостях, направленная на распространение по империи как информации, так и моделей статусного потребления. Сами церемонии были организованы таким образом, чтобы привлечь несколько уровней аудитории: приглашенных гостей (участие в придворной церемонии), население города (процессии и иллюминации) и внешних наблюдателей. Последние должны были донести до своих дворов информацию о церемониях и ритуалах новой европейской столицы. Это, пожалуй, - основная политическая составляющая церемоний, целью которых было убедить европейцев в надежности России как военного и политического союзника. Пребывание двора в городе легитимировало и сам Петербург, и было ответом на европеизацию. Тем не менее, православие продолжало играть центральную роль в ритуальной культуре двора: придворный календарь к 176о-м годам представлял собой смесь традиционных и новых элементов, а династические торжества несли на себе традиционные для русской культуры черты персонализации власти, придавая российскому двору определенную особенность (с. $69,157)$.

Новые социальные пространства создавались и физически - через архитектуру (Зимний дворец как фокус, комплекс, инкорпорировавший и близлежащие дворцы знати), и через взаимодействие как внутри аристократической верхушки, так и за ее пределами с верхним слоем городского населения в определенных топографических 
пространствах, например, в Летнем саду. Такие целенаправленно создававшиеся двором пространства социального взаимодействия разбираются автором в четвертой главе. В петровское время социальные пространства Петербурга, предназначенные для элиты, как показывается в первой главе, были открыты и для других слоев. Это, по мнению Кинана, свидетельствует о стремлении царя-преобразователя создать городское сообщество на основе более широкого слоя населения, вообще сформировать инклюзивные формы коммуникации. Последовавшее затем ограничение этой “открытости” символизировало желание дворянства, но не самого двора, обеспечить сохранение контроля над ключевыми пространствами власти и влияния, близкими к правителю (с. 27). Обратную тенденцию историк отмечает начиная с 1740-х годов: для более широких слоев дворянства и других групп петербургского общества расширяется доступ к определенным событиям (“публичным” маскарадам и театральным представлениям), а также и физическим пространствам (опера и Летние сады). Доступ тех или иных социальных страт в каждый из трех Летних садов регулировался двором: он был расширен Елизаветой Петровной сравнительно с предшествующим царствованием, однако критерии доступа оставались строгими. Начиная с 1752 года посещать сады могли не только высшие чины Табели о рангах, послы и высшие офицеры, но и все дворянство и даже купечество. Простолюдины, однако, исключались. Как было организовано это разграничение? Интериоризировалось ли оно? Какими были формы непосредственного контроля доступа в сад? Эти вопросы Кинан, к сожалению, упускает из виду. Определенно ясно, что главную роль играл формальный критерий: подобно одежде для дворян, отсутствие бороды у купца указывало на уже европеизировавшегося представителя непривилегированного сословия, готового “прогуливаться" вместе с “публикой." Насколько правомерно говорить о доступе конкретных социальных групп в отсутствие точных данных? Ведь в объявлениях о публичных маскарадах или спектаклях, открытых для публики, оговаривалась лишь обязанность быть одетым “прилично” или “не гнусно” (быть в маске, если требовалось). Поскольку одежда становится условием доступа к определенным пространствам и событиям, то есть эти требования исключали низшие социальные слои (с. 11), то сокращение дистанции с Европой для одних означало изъятие из процесса европеизации значительных групп населения.

В последней, пятой главе автор вновь уходит от исследования пространств, заявляя, что он переходит к изучению людей, заполнявших эти новые пространства. Однако в сущности автор описывает несколько сфер - источников новых практик (новые образовательные учреждения, воспитательную литературу), а также новые способы социального взаимодействия, проявлявшиеся в распространении танцев (здесь автор подчеркивает, что в раннее Новое время это был в первую очередь способ дисциплиинрования и контроля над физическими движениями), культуре нарядов и ухода за телом. Европейские моды и аксессуары хотя и вводились сверху и часто насильственно, распространялись не только среди элиты, но среди групп городского населения в этот период (с. 154). Теоретически это должно было минимизировать физические и до определенной степени культурные отличия между русскими и их современниками в Европе, однако о способах ассимиляции и усвоения этих нововведений автор ничего не сообщает.

Выше уже говорилось о том, что “европеизация” - один из ключевых терминов монографии Кинана. Еще один, не менее важный для него, но, на мой взгляд, не полностью проработанный автором, - social spaces. К сожалению, автор не уделяет 
должного внимания теоретической стороне вопроса - происхождению термина, его роли в современных социальных и гуманитарных науках. Вообще, методология исследования определенно является слабым местом монографии. Теоретизированию автор предпочитает эмпирические сведения источников (законодательства, мемуаров и архивных документов: Министерства двора, журналов дежурных генераладъютантов и из коллекции именных указов и высочайших повелений Сенату из фондов РГИА; а также из упоминавшегося выше фонда Калинкинской комиссии из РГАДА), выстраивая их тематически: строительство и формирование новой городской среды; попытки регулирования отдельных сфер городской жизни и субкультур и деятельность полиции; двор, его “календарь праздников,” церемонии и празднества; взаимодействие двора, элиты и “групп городского населения" при дворе и на представлениях.

Между тем, концепт social spaces - один из самых продуктивных и перспективных инструментов исследования в современных социальных науках, в том числе применительно и к истории имперской России. ${ }^{12}$ Концепт “социальных пространств" - результат “пространственного поворота” (spatial turn) в социальных науках. Развивающий теории Энтони Гидденса и Пьера Бурдье, этот концепт отвергает представление о пространстве как о до- или а-исторической величине. Человек предстает фундаментальной составляющей пространства. Он физически присутствует в пространстве и своей деятельностью связывает объекты, размещенные в пространстве. ${ }^{13}$ Дуализм между естественными и социальными пространствами уничтожается в пользу единого “социального пространства взаимодействия.” ${ }^{4}$ В монографии Кинана этот концепт, к сожалению, не используется в полную силу. Мы видим “взаимодействующие” между собой “социальные группы” - элиту, купечество, “горожан” (urban groups). По сути, они являются в монографии просто ярлыками. Ни формальные границы этих групп, ни неформальные или экономические признаки никак специально не оговорены, а результаты их взаимодействия остаются в тени, за исключением самого процесса европеизации. Однако говорить о распространении этого процесса на все общество, или на его части, невозможно, не показав, как и какими именно представителями этих социальных страт - аудитории церемоний и участников праздников - этот процесс интериоризировался. Ни людей, ни их деятельности, формирующих социальные пространства, о которых идет речь, в монографии не обнаруживается. Возможно, однако, что это не есть авторская недоработка. Трудов по истории России XVIII века, в которых бы успешно применялась эта методология, очень продуктивная для более позднего периода, пока нет. Причиной тому, как представляется, - отсутствие источников личного происхождения, возникших внутри самих этих пространств и описывающих их изнутри, а не снаружи, как это происходит в случае законодательства или мемуаров, написанных иностранцами, принадлежавшими к военной и политической элите. Кстати, использование документов Калинкинской комиссии является одним из шагов

\footnotetext{
${ }^{12}$ См., напр., новейшую монографию: F. B. Schenk, Russlands Fahrt in die Moderne: Mobilität und sozialer Raum im Eisenbahnzeitalter (Stuttgart: Franz Steiner Verlag, 2014); а также: H.-Ch. Petersen, "On the Margins of Urban Society? Inequalities and the Formation of Social Space in a Metropolis of Modern Age - St. Petersburg 1850-1914," InterDisciplines. Journal of History and Sociology 2:1 (2011), 85-112, URL: http://www.interdisciplines.org/bghs/index.php/indi/article/view/29/25 и др. работы автора.

${ }^{13}$ См.: M. Löw, Raumsoziologie (Frankfurt/M.: Suhrkamp, 2001); M. Löw, S. Steets, S. Stoetzer, Einführung in die Stadt- und Raumsoziologie (Opladen: Barbara Budrich Verlag, 2007).

${ }^{14}$ Приводится по: H.-Ch. Petersen, "On the Margins of Urban Society?," 89.
} 
в этом направлении. Документы полиции и других репрессивных или контролирующих органов как источник очень продуктивны в этом отношении, поскольку допросы, пусть даже и переписанные канцелярскими служителями, позволяют реконструировать “социальные пространства" не только и не столько элиты, сколько иных слоев общества.

Существенным новшеством в работе Пола Кинана является исследование церемоний торжественного въезда в Санкт-Петербург коронованного в Москве правителя/правительницы. Обычно в литературе, в том числе и в уже ставшей классической работе Р. Уортмана, рассматриваются коронации в Москве и предшествовавшие ей торжественные въезды в старую столицу. В целом книга Кинана подводит читателя к мысли о том, что Россия XVIII века - скорее Европа, чем Московия с ее неопределенной культурно-географической принадлежностью. Более того, сама книга очень “европоцентрична”: мало явлений из описанных в ней не имели своих аналогов в жизни других европейских стран. Однако был ли Петербург источником нормы или так и оставался исключением? Задал ли он модель европеизации для всей империи? Эти поставленные в монографии Кинана вопросы задают определенную рамку для будущих исследований по социальной истории России. 